\title{
Cytoprotective effect of lithium against spontaneous and induced apoptosis of lymphoid cell line MOLT-4
}

\author{
K. Pietruczuk, A. Jóźwik, K. Ruckemann-Dziurdzińska, E. Bryl, J.M. Witkowski
}

Department of Pathophysiology, Medical University of Gdańsk, Poland

\begin{abstract}
Lithium (Li) is still useful in the treatment of bipolar disorder. Cellular mechanisms of Li action are not fully understood and include some cytoprotective properties. Data concerning Li effect on the apoptotic mechanisms in cells other than neurons are fragmentary and contradictory. We have investigated anti-apoptotic activity of Li in a lymphoid derived MOLT-4 cell line. Spontaneous and camptothecin-induced apoptosis was analyzed in cells treated with $0-20 \mathrm{mM}$ Li carbonate. Early apoptosis was identified as significant mitochondrial depolarization (JC-1 staining). Later stages of apoptosis were estimatied with annexin V binding and by the proportion of cells containing sub-G1 amounts of DNA (PI staining). We have observed a biphasic effect of Li on the proportion of spontaneously apoptotic cells;namely, low (therapeutic) concentrations of $\mathrm{Li}$ had a significant effect stabilizing the mitochondrial membrane polarization, while 10 and $20 \mathrm{mM} \mathrm{Li}$ increased apoptosis. The latter could be seen both as mitochondrial depolarization as well as an increased proportion of subG1 cells, accompanied by reduced proportion of $\mathrm{S}$ phase cells. Li at concentrations above $2 \mathrm{mM}$ had a significant, dosedependent, anti-apoptotic effect on the cells undergoing camptothecin induced apoptosis. In conclusion, demonstrated cytoprotective effect of $\mathrm{Li}$ is at least partially related to stabilization of mitochondrial membrane potential and to the reduction of DNA damaging effects in proliferating cells; both may form part of the mechanism through which Li is useful in therapy of bipolar disorder, but may have more general consequences.
\end{abstract}

Keywords: lithium, bipolar disorder, cytoprotection, apoptosis, camptothecin

\section{Introduction}

Lithium (Li) is the 'gold standard' for the prophylaxis of bipolar affective disorder (BPD), a disease which is characterized by recurrent episodes of mania and depression accompanied by changes in psychovegetative function, cognitive performance, and general health.

Although Li preparations have been used for over 50 years, the cellular mechanisms of its action and how it exerts its therapeutic effect remain not fully understood. The pathophysiology of BPD is complex and still unclear but $\mathrm{Li}$ seems to target at least several abnormalities observed in mood disorders. Substituting for sodium, Li stabilizes numerous cellular processes [1]. It has a direct influence on signal transduction by modulating second messengers synthesis. Li was also shown to modulate glutaminergic and GABA-ergic neurotransmission $[2,3]$.

Correspondence: J.M. Witkowski, Dept. of Pathophysiology, Medical University of Gdańsk, Dębinki 7, 80-211 Gdańsk, Poland;tel./fax. (+4858) 3491510, e-mail:jawit@amg.gda.pl
Mood disorders are not only neurotransmission defects but are linked with structural changes of the nervous system and profound rearrangements in other integrative systems of the body [4]. More and more glial, neuroendocrine and immunologic dysfunctions seem to be recognised as contributing to mood disorders' pathogenesis [5-8]. In this context possible cytoprotective capacity of lithium salts, although debated, seems very promising for both neuron and glial regeneration and for possible preservation of the intact function of the immune cells [9-12].

Cytoprotective effects of $\mathrm{Li}$ are mainly attributed to: (1) increasing amounts of cytoprotective proteins such as Bcl-2 and decreasing proapoptotic proteins Bax and p53, (2) inhibition of glycogen synthetase kinase-3 (GSK-3) and (3) protein kinase C (PKC) activation $[9,13-16]$. Thus, it is conceivable that affecting the same mechanisms of survival or death $\mathrm{Li}^{+}$may exert a cytoprotective effect on other cell types. However, available data concerning the mechanisms of $\mathrm{Li}$ effects on cells other than neurons including the immune system cells are fragmentary and contradictory $[7,9,17-24]$. In this work we have tested the hypoth- 
A
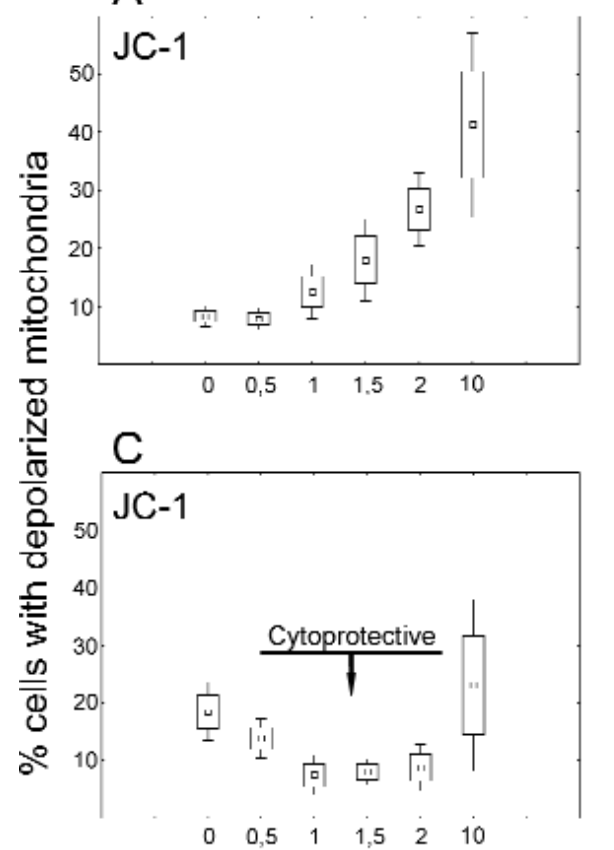

B

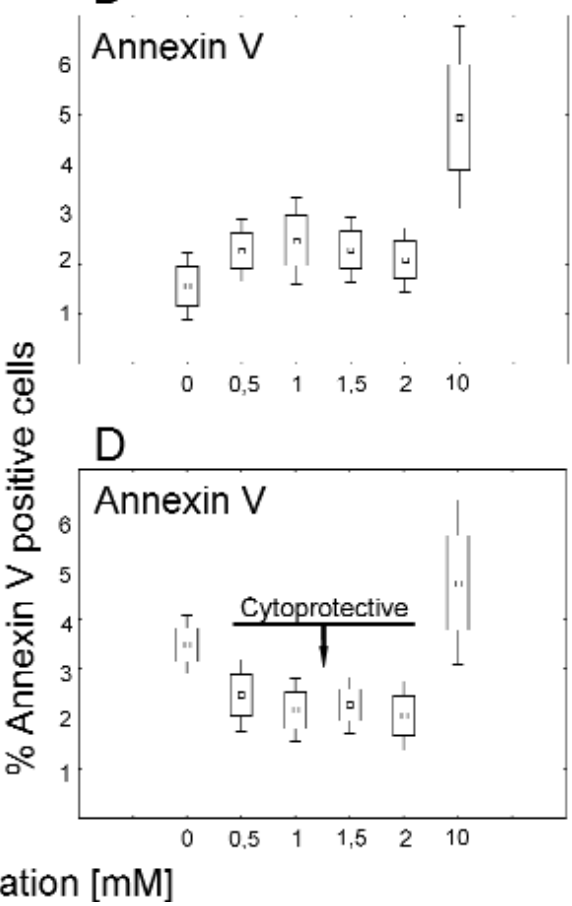

Fig. 1. Therapeutic concentrations of lithium exert cytoprotective effect against camptothecin-induced apoptosis of MOLT-4 lymphoid cells. The experiment was performed as in Materials and Methods. Cells were incubated untreated $(\mathbf{A}, \mathbf{B})$ or treated with camptothecin (C,D) for 4 hours without or with indicated concentrations of $\mathrm{Li}^{+}$and the proportion of early apoptotic cells was assessed by detection of mitochondrial membrane depolarization with JC-1 $(\mathbf{A}, \mathbf{C})$ and by membrane symmetrization with Annexin V binding (B,D). Significant increase of early apoptotic cells $(p<0.05)$ could be seen in the samples treated with above $1.5 \mathrm{mM} \mathrm{Li}^{+}$only $(\mathbf{A}, \mathbf{B})$, while lithium concentrations between 0.5 and $2 \mathrm{mM}$ were significantly reducing the proportion of apoptotic cells in camptothecin-treated samples $(\mathbf{B}, \mathbf{D}) ; \mathrm{p}<0.01$ for all $\mathrm{Li}^{+}$concentrations marked as 'cytoprotective'. Box-andwhisker plots show mean, $\pm \mathrm{SD}$, and \pm SEM, N=6. esis of the general anti-apoptotic activity of Li salts in non-neuronal cells of lymphoid derivation.

\section{Materials and methods}

MOLT-4 cells were a courteous gift of Medical Chemistry Department, Medical University of Gdańsk. Cell culture media, antibiotics (penicillin/streptomycin) and fetal bovine serum (FBS), lithium carbonate (Li2CO3), campthotecin, Hoechst 33342, 5,5',6,6'tetrachloro-1,1',3,3' tetraethylbenzimidazolycarbocyanine iodide (JC-1), RNAse, propidium iodide (PI) and Tween were purchased from Sigma-Aldrich (Germany). Annexin-V-FLUOS Staining Kit was from Roche and all the cytometry consumables were from BD Biosciences (Belgium).

Cell culture and drug treatment. Cells were cultured at $37^{\circ} \mathrm{C}$ in RPMI medium supplemented with $10 \% \mathrm{FBS}, 100 \mathrm{U} / \mathrm{ml}$ penicillin and $100 \mu \mathrm{g} / \mathrm{ml}$ streptomycin in a $95 \%$ air, $5 \% \mathrm{CO}_{2}$ humidified incubator. Cells were seeded at $0.5 \times 10^{6}$ cells per $\mathrm{ml}$ in 24 well plates and grown without or with Li carbonate added to the final concentration of $0.5 \mu \mathrm{M} ; 1 \mu \mathrm{M} ; 1.5 \mu \mathrm{M}$ (as equivalent of the therapeutic Li concentrations) and $2 \mu \mathrm{M} ; 10$ and $20 \mu \mathrm{M}$, in the presence or absence of $1 \mu \mathrm{g} / \mathrm{ml}$ of campthotecin for 4, 24, 48 and 72 hours. At times specified cells were harvested, washed with PBS and immediately further processed. Early apoptosis was identified as significant mitochondrial depolarization of cells stained with fluorescent mitochondrial potential cyanine probe JC-1 [25-27], while later stages of apoptosis by estimation of annexin $\mathrm{V}$ binding and by detection of cells containing sub-G1 amounts of DNA by staining with propidium iodide (PI) [28-30]. Apoptotic cell morphology was visualised with a DNA binding dye - Hoechst 33342 [31].

Mitochondrial potential changes. In order to detect the mitochondrial depolarization as an early feature of the incipient apoptosis, cells were incubated with $10 \mu \mathrm{g} / \mathrm{mL} 5,5^{\prime}, 6,6^{\prime}$-tetrachloro1,1',3,3'-tetraethylbenzimidazolyl-carbocyanine iodide (JC-1) for
15 minutes at room temperature and their green and red fluorescence corresponding to JC-1 monomers and aggregates respectively was assessed by FACS. Cells exhibiting an increase of green fluorescence as compared to the control were considered to have their mitochondria depolarized.

Annexin $\mathbf{V}$ binding. Later stage of apoptotic process, the membrane symmetrization leading to the externalization of the phosphatidylserine was assessed by Annexin V binding, while late apoptotic and necrotic cells were excluded by simultaneous PI staining using the Annexin-V-FLUOS Staining Kit (Roche). Cells were suspended in the binding buffer and incubated with FITCconjugated annexin V and PI for 15 minutes at room temperature, then immediately analyzed by FACS.

Cell cycle and apoptosis analysis by DNA content. Latest stages of apoptosis leading to depletion of apoptotic cells of their DNA, as well as the proportion of cells in various phases of the cell cycle (G1, S, G2/M) were assessed after staining cellular DNA with the PI. Cells were fixed with ice cold ethanol, washed and incubated with the staining mixture containing Tween-20, RNAse and PI for 15 minutes at $37^{\circ} \mathrm{C}$, then analyzed by FACS. All cytometric analyses were performed using the FACScan flow cytometer (BD Biosciences). Raw data were acquired with dedicated CellQuest software (BD Biosciences) and analyzed with WinMDI 2.9 (J. Trotter; The Scripps Institute).

Hoechst 33342 staining. Harvested cells were stained with 5 $\mu \mathrm{g} / \mathrm{ml}$ Hoechst 33342 in PBS. Stained cells were transferred onto microscopic slides and analyzed under the fluorescence microscope Eclipse TS100 (Nikon) with the 400-420 nm bypass filter. Photographs were collected using NIS Elements Nikon software.

Statistical analysis. All statistical analyses were performed with Statistica 7.1 software under the Medical University of Gdańsk license agreement. P-values of $\leq 0.05$ were taken to be significant in all tests. 


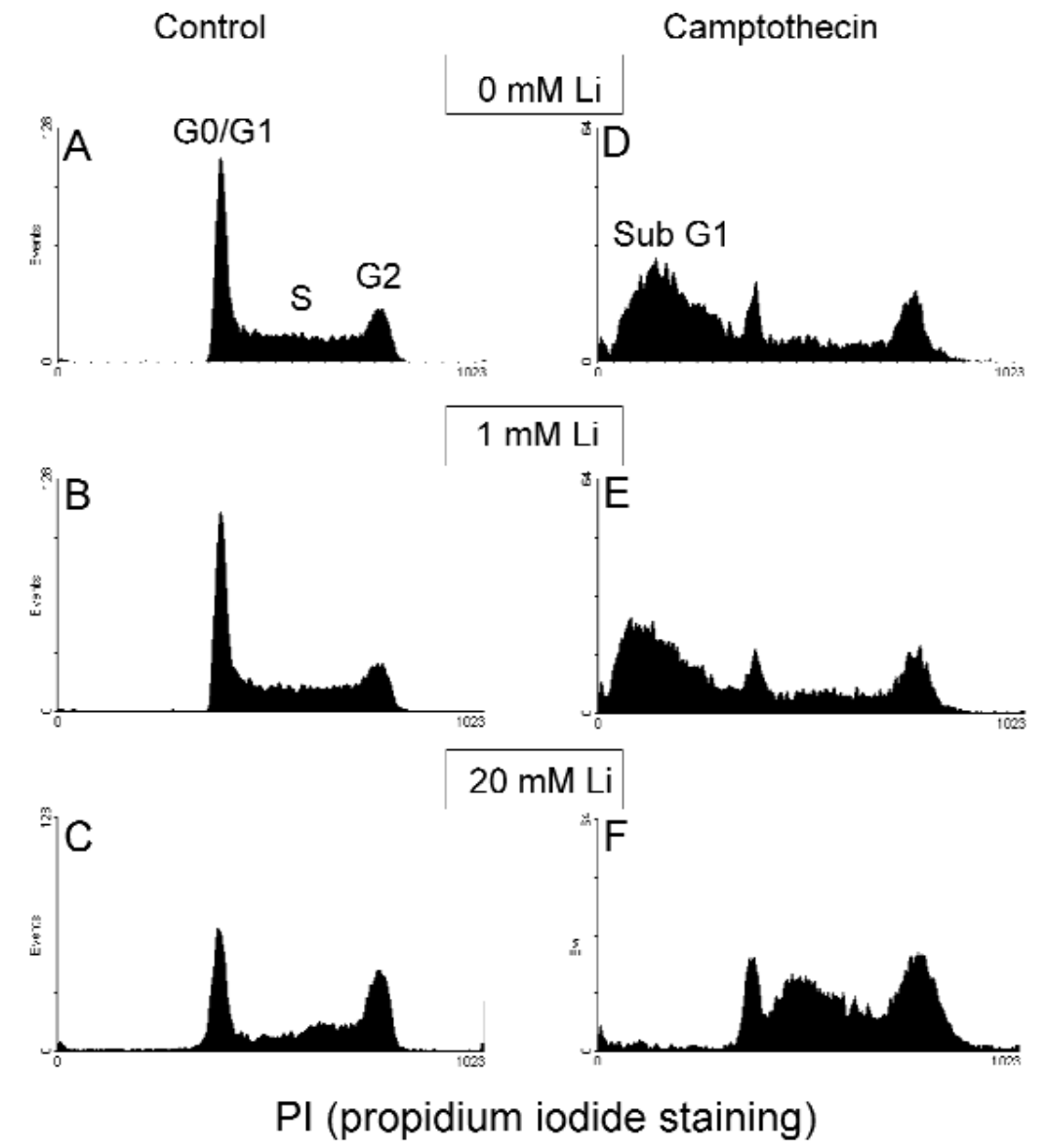

Fig. 2. Supratherapeutical concentrations of $\mathrm{Li}^{+}$protect the camptothecin-treated cells from apoptotic DNA loss. MOLT-4 cells were incubated without (A,D), with $1 \mathrm{mM}$ $\mathrm{Li}^{+}(\mathbf{B}, \mathbf{E})$ or with $20 \mathrm{mM} \mathrm{Li}^{+}(\mathbf{C}, \mathbf{F})$ for 24 hours, without (A-C) or with simultaneous presence of camptothecin as in Materials and Methods (D-F). DNA contents was estimated by flow cytometry using the propidium iodide (PI) staining . $1 \mathrm{mM}$ lithium had no apparent effect on the proportion of sub-G1 cells either untreated (B) or camptothecin treated $(\mathbf{E})$. Lithium at $20 \mathrm{mM}$ reduced the proportion of camptothecin-free cells in Sphase $(\mathbf{C})$, and markedly reduced the proportion of subG1 cells among those treated with camptothecin, with simultaneous increase of S and $\mathrm{G} 2 / \mathrm{M}$ cells' proportion $(\mathbf{F})$. Cytometric histograms illustrate one experiment representative for three giving the same results (compare Fig. 3 and 4).

\section{Results}

There were significant differences in the effect of $\mathrm{Li}$ salt on the various stages of the apoptotic process, depending on its being spontaneous or camptothecininduced.

First, we have observed a mildly proapoptotic effect of $\mathrm{Li}$ on the proportion of spontaneously apoptotic MOLT- 4 cells assessed by the mitochondrial depolarization, where the proportion of depolarized cells started to rise at $1 \mathrm{mM} \mathrm{Li}^{+}$and then rose proportionally to the concentration of lithium salt, reaching significant difference from the untreated control (Fig. 1 A). This effect was generally paralleled by the appearance of apoptotic, Annexin V - binding cells upon treatment with $10 \mathrm{mM} \mathrm{Li}^{+}$(Fig. $1 \mathrm{~B}$ ).

Interestingly, the effect exerted by $\mathrm{Li}^{+}$over MOLT4 cells induced to undergo apoptosis by treatment with the topoisomerase II inhibitor, camptothecin, was clearly biphasic. Namely, low (therapeutic) concentrations of $\mathrm{Li}^{+}$had a significant effect stabilizing the mitochondrial membrane potential (Fig. $1 \mathrm{C}$ ) and decreasing the external surface binding of Annexin $\mathrm{V}$ (Fig. $1 \mathrm{D}$ ), while $10 \mathrm{mM} \mathrm{Li}^{+}$increased the proportion of early apoptotic cells enumerated both ways above the control (untreated) level (Fig. 1 C, D).
Also the effect of $\mathrm{Li}^{+}$on late apoptosis (cellular DNA fragmentation and removal) depends on its concentration and on the manner of apoptosis induction. Thus, in the untreated cells, only the supraclinical (10 and $20 \mathrm{mM}$ ) concentrations of $\mathrm{Li}^{+}$induced significant apoptosis as judged by the appearance of cells containing sub-G1 amounts of DNA (Fig. 2 A-C, Fig. 3 A).

Increased proportion of sub-G1 cells appearing due to $\mathrm{Li}^{+}$treatment was accompanied by reduced proportion of S phase cells, but this effect showed only after 24 hour treatment (Fig. 3 B) and disappeared after 48 hours of incubation with $\mathrm{Li}^{+}$, at which time the proportion of sub-G1 cells in 10 and $20 \mathrm{mM} \mathrm{Li}^{+}$-treated samples did not differ from that seen after 24 hours (Fig. 3 C, D).

Interestingly enough, while the effect on $\mathrm{Li}^{+}$in untreated cells was rather pro-apoptotic, that exerted over the MOLT-4 cells in which apoptosis was induced by camptothecin (blockade of topoisomerase), was clearly anti-apoptotic and cytoprotective. This effect could be demonstrated for all three phases of induced apoptosis. Thus, $\mathrm{Li}^{+}$at $0.5-2 \mathrm{mM}$ significantly decreased the proportion of cells that exhibited mitochondrial depolarization (Fig. $1 \mathrm{C}$ ) and the proportion 

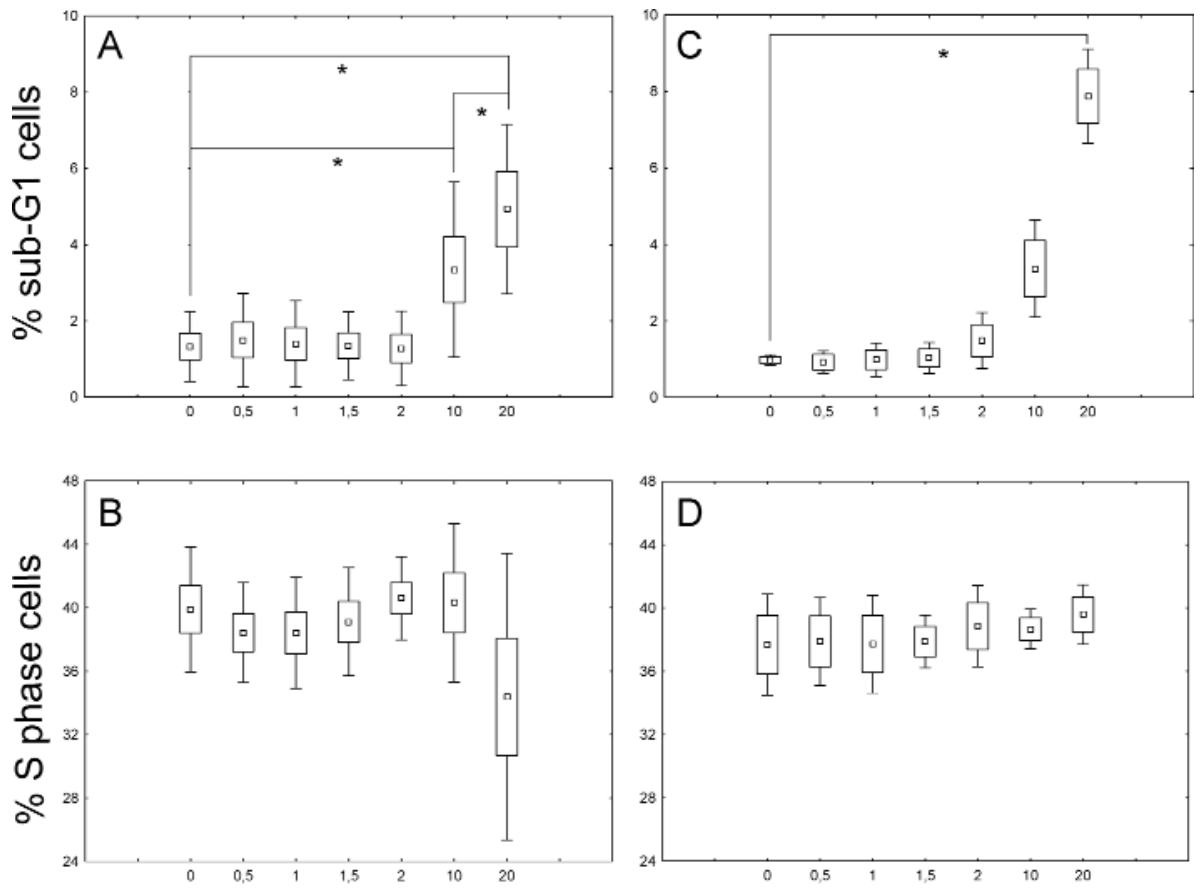

Li concentration [mM]
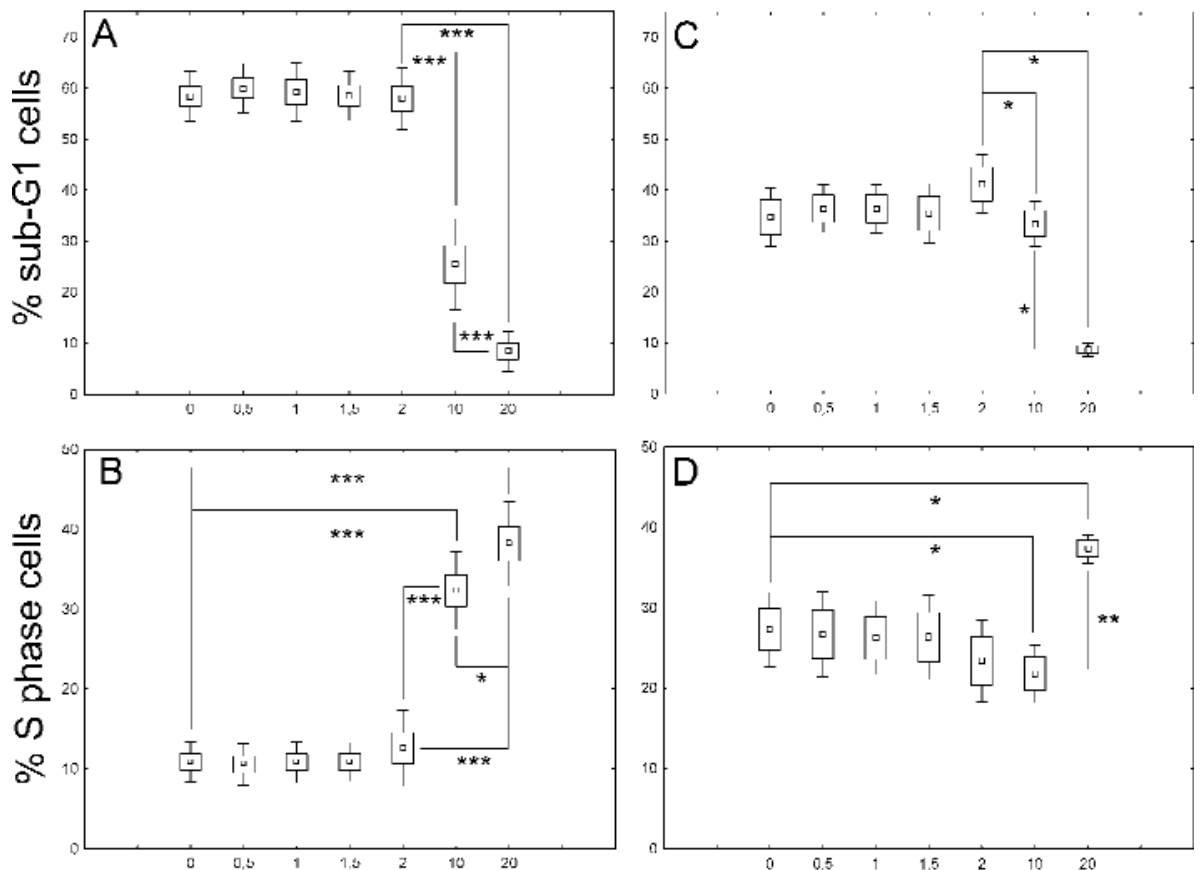

Li concentration [mM]
Fig. 3. Supratherapeutical concentrations of $\mathrm{Li}^{+}$are inducing increase in spontaneous apoptosis of MOLT-4 cells. Proportions of sub-G1 and S-phase cells were assessed by flow cytometry after 24 $(\mathbf{A}, \mathbf{B})$ or 48 hours of treatment with indicated concentrations of $\mathrm{Li}^{+}(\mathbf{C}, \mathbf{D})$ as in Materials and Methods. 10 and $20 \mathrm{mM}$ $\mathrm{Li}^{+}$resulted in significant increase of the proportion of subG1 cells after 24 hours, as compared to untreated control, and for $20 \mathrm{mM} \mathrm{Li}^{+}$also after 48 hours $(\mathrm{N}=3$, $* p<0.001)$. The effect was reciprocated by loss of S-phase cells seen in 24-hour assay (B) but not after 48 hours (D).
Fig. 4. Supratherapeutical concentrations of $\mathrm{Li}^{+}$protect the camptothecintreated cells from apoptotic DNA loss. Proportions of subG1 and S-phase cells were assessed by flow cytometry after $24(\mathbf{A}, \mathbf{B})$ or 48 hours of treatment with indicated concentrations of $\mathrm{Li}^{+}(\mathbf{C}, \mathbf{D})$ as in Materials and Methods. 10 and 20 $\mathrm{mM} \mathrm{Li}^{+}$resulted in significant decrease of the proportion of subG1 cells after 24 and 48 hours of simultaneous treatment with $\mathrm{Li}$ and camptothecin $(\mathbf{A}, \mathbf{C})$, as compared to untreated control (not shown) and to $2 \mathrm{mM} \mathrm{Li}^{+}$-treated cells $(\mathrm{N}=3, * \mathrm{p}<0.01, * * * \mathrm{p}<0.0001)$. The effect was reciprocated by significant increase of S-phase cells seen in 24and 48-hour assay (B,D;N=3, $* \mathrm{p}<0.01$, $* * \mathrm{p}<0.001, * * * \mathrm{p}<0.0001)$. of Annexin V - biding cells (Fig. 1 D). On the other hand, appreciable and significant effect of $\mathrm{Li}^{+}$preventing the formation of sub-G1 cells could be seen only at 10 and $20 \mathrm{mM}$ of lithium salt, after both 24 and 48 hour treatment (Fig. 2 D-F, Fig. 4 A, C). Some concentration dependency of the anti-apoptotic effect of
$\mathrm{Li}^{+}$on camptothecin-treated cells could also be seen;thus, $2 \mathrm{mM} \mathrm{Li}^{+}$had no protective effect, while that of $20 \mathrm{mM} \mathrm{Li}^{+}$was significantly higher than that exerted by $10 \mathrm{mM} \mathrm{Li}^{+}$(Fig. 4). Accordingly, morphological changes in the nuclei of MOLT-4 cells treated with either $\mathrm{Li}^{+}$or camptothecin only, or with their 

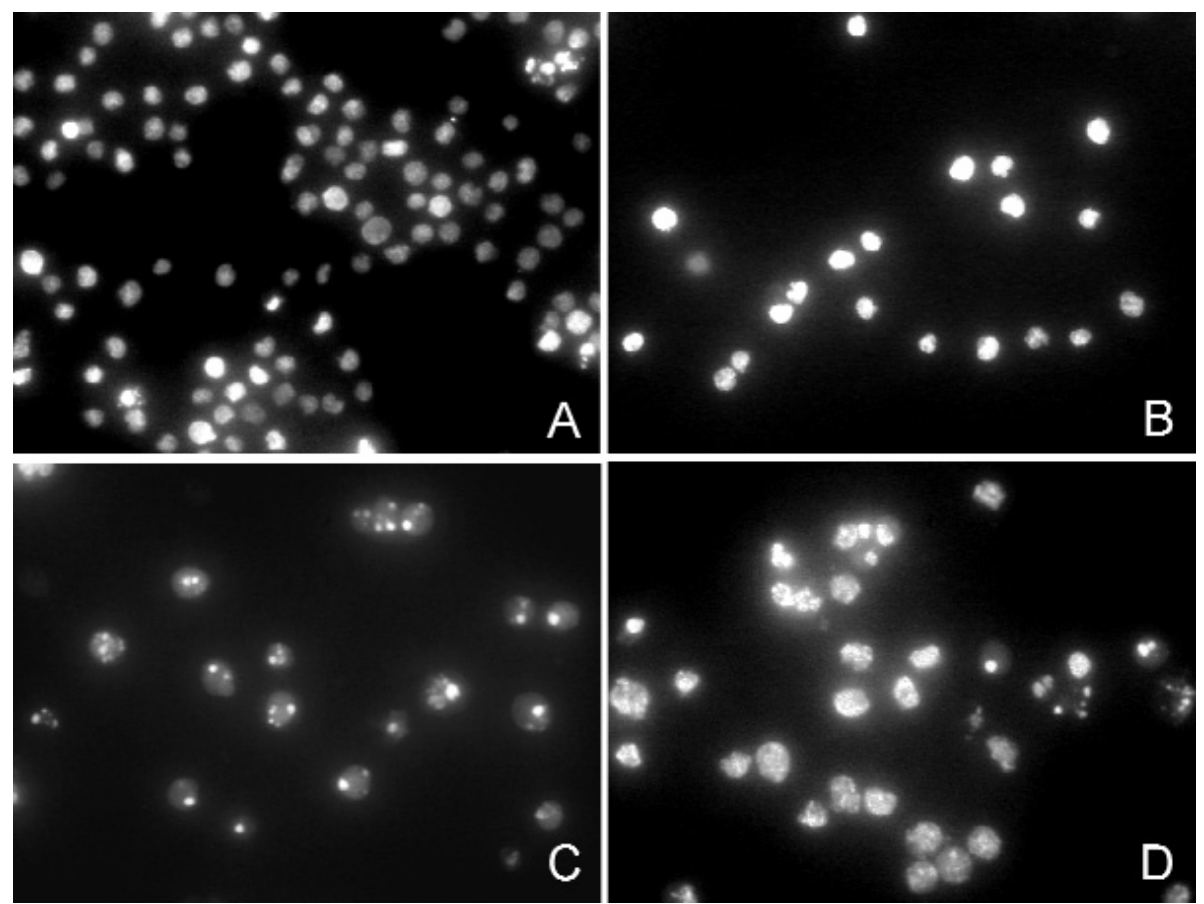

Fig. 5. Supratherapeutical $\mathrm{Li}^{+}$prevents DNA damage and chromatin fragmentation induced by camptothecin. Cells were cultured without treatment (A) with $2 \mathrm{mM} \mathrm{Li}^{+}$(B) with $2 \mathrm{mM} \mathrm{Li}^{+}$and camptothecin $(\mathbf{C})$ or with $20 \mathrm{mM} \mathrm{Li}^{+}$ and camptothecin for 72 hours, stained with Hoechst 33342 and their fluorescence recorded as in Materials and Methods. Cells treated with camptothecin and therapeutical $\mathrm{Li}^{+}(2 \mathrm{mM})$ show general signs of apoptotic chromatin fragmentation $(\mathbf{C})$ which is absent from most cells treated with camptothecin in te presence of $20 \mathrm{mM} \mathrm{Li}^{+}$ (D). Pictures show the representative results of one of three experiments. combination, could be seen. Thus, treatment with $\mathrm{Li}^{+}$ only did not change the proportion of apoptotic cells displaying fragmented, focally condensed chromatin (Fig. 5 A, B), while treatment with camptothecin only resulted in the vast majority of the cells to become morphologically apoptotic, as judged by Hoechst 33342 staining (Fig. 5 C). Finally, $20 \mathrm{mM} \mathrm{Li}^{+}$added simultaneously with camptothecin completely abolished its proapoptotic level (Fig. $5 \mathrm{D}$ ).

Similarly to the effects of $\mathrm{Li}^{+}$on the proportions of otherwise untreated sub-G1 and S phase cells, also the $\mathrm{Li}^{+}$-dependent reduction of sub-G1 fraction of MOLT4 cells treated with camptothecin was reciprocated by a significant increase in the proportion of cells in Sphase of the cycle (Fig. 2 F, Fig. 4 B). Unlike in the case of untreated cells, the effect was preserved also in the cells that were treated with $\mathrm{Li}^{+}$and camptothecin over 48 hours (Fig. 4 D).

\section{Discussion}

We have demonstrated here a variable, dose dependent effect of treatment with therapeutic and supratherapeutic doses of lithium salts on the survival and spontaneous and camptothecin-induced apoptosis of MOLT4 cells. Thus, in otherwise untreated cells, $\mathrm{Li}^{+}$acted mostly pro-apoptotically, and that mainly at supratherapeutic concentrations above $2 \mathrm{mM}$, while in the case of camptothecin-induced apoptosis, therapeutic $\mathrm{Li}^{+}$ concentrations were anti-apoptotic and thus cytoprotective. These effects were seen by any means of apoptosis assessment, including initial mitochondrial depolarization (JC-1 monomer fluorescence), membrane symmetrization (Annexin V binding) and DNA fragmentation/loss, suggesting that $\mathrm{Li}^{+}$is either directly or indirectly affecting all of them.

The process of apoptosis is controlled by a diverse range of cell signals, which may originate extracellularly or intracellularly. There are two main apoptosis pathways:(1) internal (mitochondrial) with caspase-9 playing the main role and (2) Fas or TNF receptor induced with central role of caspase-8. A number of proapoptotic and cytoprotective proteins take part in apoptosis regulation. In response to apoptosis-inducing signals p53 regulates concentrations of some of them. Level of Bax protein increases and of Bcl-2 decreases. Bcl-2/Bax ratio in the mitochondria determines the release of cytochrome c leading to apoptosome formation. The apoptosome consists of cytochrome c, Apaf-1 protein and procaspse-9 and its formation activates caspase cascade leading the cell to apoptosis [31-33]. Thus, the mechanisms of both proand anti-apoptotic $\mathrm{Li}^{+}$activity seen by us may be complex.

Concerning its modulation of the mitochondrial potential, $\mathrm{Li}^{+}$is known to substitute for $\mathrm{Na}^{+}$, and to accumulate in the cell displacing intracellular $\mathrm{Na}$ and in turn also intracellular $\mathrm{Ca}$ [1]. Thus, substitution of sodium ions by Li stabilizes numerous intracellular processes and may be responsible for its action on mitochondria [2].

Chronic $\mathrm{Li}$ administration has been reported to induce a robust elevation in the levels of the cytoprotective protein $\mathrm{Bcl}-2$ when measured in the frontal cortex, hippocampus, and striatum. Elevated Bcl-2 not only protects the neurons from apoptosis but has also 
been proven to result in better axonal regeneration in mammals [34-37]. In rabbits, pretreatment with lithium prevented aluminum-induced cytochrome c translocation and thus initiation of apoptosis [38]. Li can also induce decrease in Bax and p53 proteins and inhibits procaspase-3 cleavage to caspase-3 [38]. The latter is supported by the observation that $\mathrm{Li}$ prevents apoptosis evoked by different substances including colchicine exerting its action through caspase- 3 activation [39-41], which in fact agrees with our observations.

Li also influences glycogen metabolism which is involved in cell proliferation, differentiation and apoptosis $[42,43]$. GSK-3 causes phosphorylation which inhibits glycogen synthase, simultaneously glycogenolysis is activated. GSK-3 has numerous cellular targets, namely transcription factors, cytoskeleton proteins and cell division involved molecules including AP-1, cyclic AMP response element binding protein (CREB), heat shock factor-1, nuclear factor of activated $\mathrm{T}$ cells NF-AT, c-Myc, beta-catenin, CCAAT/ enhancer binding protein, and NF?B. Generally, active GSK-3 is proapoptotic and its inhibition is antiapoptotic $[44,45]$. Li inhibits GSK-3 both directly (substituting for cofactory magnesium ions) and indirectly. Other changes resulting from Li-induced GSK-3 inhibition were shown in proliferating thyreocytes, namely an increase in Jun bound to DNA, CREB activity reduction and lower MAP1B and Tau phosphorylation [46-49]. Wnt glycoproteins, belonging to the pathway activated by the GSK-3 inhibition (e.g. resulting from lithium treatment), are involved in embryogenesis, stem cell development, cell proliferation and axonal plasticity [50]. In the absence of Wnt, GSK-3 phosphorylates beta-catenins leading to their degradation, which is prevented by $\mathrm{Li}^{+}$. Beta-catenins, accumulating in the cell nuclei when GSK-3 is inhibited, bind with T-cell-specific transcription factor (TCF) and activate a number of genes, possibly involved in the cell survival $[46,47]$.

Another proposed Li action is through protein kinases which catalyse phosphorylation of the target proteins and subsequently take part in the regulation of the cell respose to the stimuli. Li treatment leads to diacyloglycerol (DAG) accumulation and activation of the protein kinase C (PKC) [46]. PKC targets two proteins, both involved in neuroplasticity, GAP-43 (growth-associated protein) and MARCKS (myristoylated alanine rich $\mathrm{C}$ kinase substrate). In cerebellar granule cells $\mathrm{Li}$ has been shown to induce axonal remodeling resembling the changes seen with GAP-43 overexpression $[46,47,51]$.

A growing body of data suggests that bipolar disease BPD is not only a defect in neurotransmission mechanisms but arises from abnormalities in synaptic and neuronal plasticity cascades, leading to an aberrant information processing in critical synapses and circuits $[3,4,12,19]$. Recent morphometric studies have been investigating potential structural brain changes in $\mathrm{BPD}$, and there is evidence from a variety of sources demonstrating significant volume reductions in several regions of CNS, as well as regional decrease in the glia and neurons numbers and sizes $[6,52,53]$.

In this context reports of a possible cytoprotective capacities of Li have been enthusiastically welcomed immediately noting that it may be important not only in mood disorders but in neurodegenerative diseases. Modulating GSK-3 activity Li reduced amyloid and tau protein phosphorylation in transgenic mice, results very promising for the possible Li use for Alzheimer disease $[10,54,55]$.

Data regarding the neuroprotective action of $\mathrm{Li}$ have been recently reviewed, showing that although postulated by many has only been proven by few [9]. It may be in line with our observation that the cytoprotective effect of Li salts is dose dependent - in our model at therapeutic concentrations the spontaneous apoptosis is prevented, while higher concentrations prove toxic and increase apoptosis. Interestingly, significant anti-apoptotic effect in capthotecin-induced model is achieved with either the therapeutic (for early stages of apoptosis, including the mitochondrial depolarization and membrane symmetrization) or supratherapeutic concentrations of lithium salts (which result in protection from DNA fragmentation and loss). Thus experimental data must be interpreted with caution before conclusions are drawn about the effect in humans in vivo.

Li administration was recently linked to reduced tumor incidence compared to the general population [56]. It was shown to reduce proliferation in tumors expressing high activity of GSK-3. In prostate cancer Li decreases the expression of multiple DNA replication-related genes, including cyclin A, cyclin E, cell division cycle 6 (cdc6), and cdc $25 \mathrm{C}$, all regulated by GSK-3 dependent E2 factor during the cell cycle [56,57].

In the light of our observations showing that the treatment with $\mathrm{Li}^{+}$not only reduced the camptothecininduced apoptosis, but in fact increased the proportion of cells in the $\mathrm{S}$ phase of the cycle, it is also important to stress, that shown cytoprotective properties of $\mathrm{Li}$, while very welcomed in some cases, might not be desirable during cytostatic treatment [58-62]. Our research clearly indicates that topoisomerase inhibitor treatment might be severely jeopardized by simultaneous administration of the Li salts. Thus, in our opinion, safety of lithium treatment during chemotherapeutic intervention should be considered and needs further evaluation.

Concluding, both the recent papers cited above and our observations presented herein suggest that 
the cytoprotective action of $\mathrm{Li}^{+}$is not limited to the neurons and may be considered a generalized phenomenon.

\section{References}

[1] Huang X, Lei Z, El-Mallakh RS. Lithium normalizes elevated intracellular sodium. Bipolar Disord. 2007;9:298-300.

[2] Shaldubina A, Agam G, Belmaker RH. The mechanism of lithium action:state of the art, ten years later. Prog. Neuropsychopharmacol. Biol Psychiatry. 2001;25:855-866.

[3] Zarate J, Carlos A, Singh JB, Carlson PJ et al. Molecular mechanisms of bipolar disorder. Drug Discovery Today: Disease Mechanisms. 2005;2:435-445.

[4] Craddock N. Genetics of mood disorders. Psychiatry. 2006;5:170-174.

[5] Schloesser RJ, Huang J, Klein PS et al. Cellular plasticity cascades in the pathophysiology and treatment of bipolar disorder. Neuropsychopharmacology. 2008;33:110-133.

[6] Konarski JZ, McIntyre RS, Kennedy SH et al. Volumetric neuroimaging investigations in mood disorders:bipolar disorder versus major depressive disorder. Bipolar Disord. 2008; $10: 1-37$.

[7] Ortiz-Dominguez A, Hernandez ME, Berlanga C et al. Immune variations in bipolar disorder:phasic differences. Bipolar Disord. 2007;9:596-602.

[ 8] Liu H, Yang Y, Chou Y et al. Immunologic variables in acute mania of bipolar disorder. J Neuroimmunol. 2004;150:116122.

[9] Fountoulakis KN, Vieta E, Bouras C et al. A systematic review of existing data on long-term lithium therapy:neuroprotective or neurotoxic? Int $J$ Neuropsychopharmacol. 2008;11:269-287.

[10] Manji HK, Moore GJ, Chen G. Lithium at 50:have the neuroprotective effects of this unique action been overlooked? Biol Psychiatry. 1999;46:929-940.

[11] Yuan P, Gould TD, Gray NA et al. Neurotrophic signaling cascades are major long-term targets for lithium: clinical implications. Clin Neurosci Res. 2004;4:137-153.

[12] Zarate CA, Singh J Jr, Manji HK. Cellular plasticity cascades:targets for the development of novel therapeutics for bipolar disorder. Biol Psychiatry. 2006;59:1006-1020.

[13] Beurel E, Kornprobst M, Blivet-Van Eggelpoël M et al. GSK$3 \beta$ inhibition by lithium confers resistance to chemotherapyinduced apoptosis through the repression of CD95 (Fas/APO-1) expression. Exp Cell Res. 2004;300:354-364.

[14] Cecchinato V, Chiaramonte R, Nizzardo M et al. Resveratrolinduced apoptosis in human T-cell acute lymphoblastic leukaemia MOLT-4 cells. Biochem Pharmacol. 2007;74: $1568-1574$

[15] Eom TY, Roth KA, Jope RS. Neural precursor cells are protected from apoptosis induced by trophic factor withdrawal or genotoxic stress by inhibitors of glycogen synthase kinase 3 . J Biol Chem. 2007;282:22856-22864.

[16] Jope RS. Lithium and GSK-3:one inhibitor, two inhibitory actions, multiple outcomes. Trends Pharmacol Sci. 2003;24: 441-443.

[17] Boufidou F, Nikolaou C, Alevizos B et al. Cytokine production in bipolar affective disorder patients under lithium treatment. J Affect Disord. 2004;82:309-313.

[18] Carlson SL, Brooks WH, Roszman TL.. Neurotransmitterlymphocyte interactions:dual receptor modulation of lymphocyte proliferation and cAMP production. J Neuroimmunol. 1989;24:155-162.

[19] Coyle JT, Duman RS. Finding the intracellular signaling pathways affected by mood disorder treatments. Neuron. 2003;38:157-160.
[20] Kappes A, Vaccaro A, Kunnimalaiyaan M et al. Lithium ions:A novel treatment for pheochromocytomas and paragangliomas. Surgery. 2007;141:161-165.

[21] Kim Y, Jung H, Myint A et al. Imbalance between pro-inflammatory and anti-inflammatory cytokines in bipolar disorder. $J$ Affect Disord. 2007;104:91-95.

[22] Lai JS, Zhao C, Warsh JJ et al. Cytoprotection by lithium and valproate varies between cell types and cellular stresses. Eur J Pharmacol. 2006;539:18-26.

[23] Lieb J. The immunostimulating and antimicrobial properties of lithium and antidepressants. J Infection. 2004;49:88-93.

[24] Rapaport MH, Guylai L, Whybrow P. Immune parameters in rapid cycling bipolar patients before and after lithium treatment. J Psych Res. 1999;33:335-340.

[25] Cossarizza A, Baccarani-Contri M, Kalashnikova G et al. A new method for the cytofluorimetric analysis of mitochondrial membrane potential using the J-aggregate forming lipophilic cation 5,5',6,6'-tetrachloro-1,1',3,3'-tetraethylbenzimidazolcarbocyanine iodide (JC-1). Biochem Biophys Res Commun. 1993;197:40-45.

[26] Reers M, Smiley ST, Mottola-Hartshorn C et al. Mitochondrial membrane potential monitored by JC-1 dye. Methods Enzymol. 1995;260:406-417.

[27] Salvioli S, Ardizzoni A, Franceschi C et al. JC-1, but not DiOC6(3) or rhodamine 123, is a reliable fluorescent probe to assess delta psi changes in intact cells:implications for studies on mitochondrial functionality during apoptosis. FEBS Lett. 1997;411:77-82.

[28] Kisielewska J, Ligęza J, Klein A. The effect of tyrosine kinase inhibitors, tyrphostins:AG1024 and SU1498, on autocrine growth of prostate cancer cells (DU145). Folia Histochem Cytobiol. 2008;46(2):185-191.

[29] Hamel W, Dazin P, Israel MA. Adaptation of a simple flow cytometric assay to identify different stages during apoptosis. Cytometry. 1996;25:173-181.

[30] Eray M, Matto M, Kaartinen M et al. Flow cytometric analysis of apoptotic subpopulations with a combination of annexin V-FITC, propidium iodide, and SYTO 17. Cytometry. 2001;43:134-142.

[31] Jasek E, Mirecka J, Litwin JA. Effect of differentiating agents (All-trans retinoic acid and phorbol 12-myristate 13-acetate) on drug sensitivity of HL-60 and NB4 cells in vitro. Folia Histochemt Cytobiol. 2008;46(3):323-330.

[32] Siegel RM. Caspases at the crossroads of immune-cell life and death. Nat Rev Immunol. 2006;6:308-317.

[33] Aggarwal BB. Signalling pathways of the TNF superfamily:a double-edged sword. Nat Rev Immunol. 2003;3:745-756.

[34] Chuang DM, Chen RW, Chalecka-Franaszek E et al. Neuroprotective effects of lithium in cultured cells and animal models of diseases. Bipolar Disord. 2002;4:129-136.

[35] Chen G, Zeng WZ, Yuan PX et al. The mood-stabilizing agents lithium and valproate robustly increase the levels of the neuroprotective protein bcl-2 in the CNS. J Neurochem. 1999;72:879-882.

[36] Chen DF, Schneider GE, Martinou JC et al. Bcl-2 promotes regeneration of severed axons in mammalian CNS. Nature. 1997;385:434-439.

[37] Manji HK, Moore GJ, Chen G. Lithium up-regulates the cytoprotective protein $\mathrm{Bcl}-2$ in the CNS in vivo:a role for neurotrophic and neuroprotective effects in manic depressive illness. J Clin Psychiatry. 2000;61(Suppl 9):82-96.

[38] Ghribi O, Herman MM, Spaulding NK et al. Lithium inhibits aluminum-induced apoptosis in rabbit hippocampus, by preventing cytochrome $\mathrm{c}$ translocation, Bcl-2 decrease, Bax elevation and caspase-3 activation. $J$ Neurochem. 2002;82:137-145.

[39] Jorda EG, Verdaguer E, Morano A et al. Lithium prevents colchicine-induced apoptosis in rat cerebellar granule neurons. Bipolar Disord. 2004;6:144-149. 
[40] Mora A, Sabio G, Gonzalez-Polo RA et al. Lithium inhibits caspase 3 activation and dephosphorylation of $\mathrm{PKB}$ and GSK3 induced by $\mathrm{K}+$ deprivation in cerebellar granule cells. J Neurochem. 2001;78:199-206.

[41] King TD, Bijur GN, Jope RS. Caspase-3 activation induced by inhibition of mitochondrial complex I is facilitated by glycogen synthase kinase-3beta and attenuated by lithium. Brain Res. 2001;919:106-114.

[42] Jope RS. Inhibition of glycogen synthase kinase-3:a potential therapeutic target of lithium. Clin Neurosci Res. 2004;4:171179.

[43] Jope RS. Lithium and GSK-3:one inhibitor, two inhibitory actions, multiple outcomes. Trends Pharmacol Sci. 2003;24: 441-443.

[44] Summers SA, Kao AW, Kohn AD et al. The role of glycogen synthase kinase 3 beta in insulin-stimulated glucose metabolism. J Biol Chem. 1999;274:17934-17940.

[45] Cui H, Meng Y, Bulleit RF. Inhibition of glycogen synthase kinase 3 beta activity regulates proliferation of cultured cerebellar granule cells. Brain Res Dev. 1998;111:177-188.

[46] Corbella B, Vieta E. Molecular targets of lithium action. Acta Neuropsychiatrica. 2003;15:316-340.

[47] Williams RSB, Harwood AJ. Lithium therapy and signal transduction. Trends Pharmacol Sci. 2000;21:61-64.

[48] Gould TD, Chen G, Manji HK. In vivo evidence in the brain for lithium inhibition of glycogen synthase kinase-3. Neuropsychopharmacology. 2004;29:32-38.

[49] Rao AS, Kremenevskaja N, Resch J et al. Lithium stimulates proliferation in cultured thyrocytes by activating Wnt/betacatenin signalling. Eur J Endocrinol. 2005;153:929-938.

[50] Salinas PC. Synaptogenesis:Wnt and TGF-beta take centre stage. Curr Biol. 2003;13:R60-2.

[51] Salinas PC, Hall AC. Lithium and synaptic plasticity. Bipolar Disord. 1999;1:87-90

[52] Rajkowska G, Miguel-Hidalgo JJ. Gliogenesis and glial pathology in depression. CNS Neurol. Disord. Drug Targets. 2007;6:219-233.
[53] Rajkowska G. Postmortem studies in mood disorders indicate altered numbers of neurons and glial cells. Biol Psych. 2000;48:766-777.

[54] Rockenstein E, Torrance M, Adame A et al. Neuroprotective effects of regulators of the glycogen synthase kinase-3beta signaling pathway in a transgenic model of Alzheimer's disease are associated with reduced amyloid precursor protein phosphorylation. J Neurosci. 2007;27:1981-1991.

[55] Phiel CJ, Wilson CA, Lee VM et al. GSK-3alpha regulates production of Alzheimer's disease amyloid-beta peptides. Nature. 2003;423:435-439.

[56] Lieb J. Antidepressants, prostaglandins and the prevention and treatment of cancer. Med Hypoth. 2007;69:684-689.

[57] Alao J P. The regulation of cyclin D1 degradation:roles in cancer development and the potential for therapeutic invention. Mol Cancer. 2007;6:24.

[58] Yang ES, Lu B, Hallahan DE. Lithium-Mediated Neuroprotection During Cranial Irradiation: A Phase I Trial. Int JRad Oncol Biol Phys. 2007;69:S586-S587.

[59] Oktem G, Bilir A, Erguven M et al. C25. Lithium for treatment and chemo-sensitization:Testing the hypothesis on SHSY5Y cells in monolayer and 3D-spheroids. Nitric Oxide. 2007; $17: 26$

[60] Shakoori A, Mai W, Miyashita K et al. Inhibition of GSK-3 beta activity attenuates proliferation of human colon cancer cells in rodents. Cancer Sci. 2007;98:1388-1393.

[61] Gauwerky CE \& Golde DW. Lithium enhances growth of human leukaemia cells in vitro. Br J Haematol. 1982;51:431438.

[62] Kucharz EJ, Sierakowski S, Staite ND et al. Mechanism of lithium-induced augmentation of T-cell proliferation. Int $J$ Immunopharmacol. 1988;10:253-259.

Submitted: 10 June, 2009 Accepted after reviews: 25 August, 2009 